\title{
Ultra-High Pool Boiling Performance and Effect of Channel Width With Selectively Coated Open Microchannels
}

\author{
Arvind Jaikumar ${ }^{1}$, Satish G. Kandlikar ${ }^{2, *}$ \\ ${ }^{1}$ Microsystems Engineering Department, Rochester Institute of Technology, 76 Lomb Memorial \\ Dr., Rochester, NY, 14623, U.S.A. \\ ${ }^{2}$ Mechanical Engineering Department, Rochester Institute of Technology, 76 Lomb Memorial \\ Dr., Rochester, NY, 14623, U.S.A. \\ E-mail Addresses: \\ Arvind Jaikumar, aj4853@ rit.edu \\ Satish G. Kandlikar: sgkeme@ rit.edu \\ *Corresponding author: \\ Satish G. Kandlikar \\ sgkeme@rit.edu, \\ Mechanical Engineering, Rochester Institute of Technology, 76 Lomb Memorial Dr., Rochester, \\ NY, 14623, U.S.A. \\ Telephone: +1-(585)-475-6728 \\ Fax: +1-(585)-475-6879
}




\begin{abstract}
Recent developments in the microelectronics industry has placed increasing demand on developing high heat flux removal systems. Pool boiling offers a simple technique without introducing complicated header configurations and moving parts. Enhancement in pool boiling is achieved by delaying critical heat flux (CHF) and increasing heat transfer coefficient (HTC), which dictates the heat removal capability of a surface. This study focuses on the effect of channel width on the performance and heat transfer mechanisms on open microchannel surfaces with three coating configurations: (i) sintered-throughout, (ii) sintered-fin-tops, and (iii) sinteredchannels. Pool boiling performance is obtained with water at atmospheric pressure for $300 \mu \mathrm{m}$, $500 \mu \mathrm{m}$ and $762 \mu \mathrm{m}$ channel widths. The separate liquid-vapor pathways in narrow channels, with sintered coatings only inside the channel, yielded an unprecedented performance with a $\mathrm{CHF}$ of $420 \mathrm{~W} / \mathrm{cm}^{2}$ based on the $1 \mathrm{~cm}^{2}$ projected area at a wall superheat of $1.7{ }^{\circ} \mathrm{C}$ at the fin top surface, resulting in an $\mathrm{HTC}$ of $2.9 \mathrm{MW} / \mathrm{m}^{2 \circ} \mathrm{C}$. High speed videos were taken to understand the underlying mechanism. Furthermore, liquid-vapor pathways were identified to explain the parametric trends observed for each selectively enhanced configuration set.
\end{abstract}

\title{
Keywords
}

Pool boiling, CHF, HTC, sintered-throughout, sintered-fin-tops, sintered-channels

\section{Introduction}

The increased number and closely packed heat emitting unit configurations of IC chips require efficient heat transfer systems to cool the devices effectively. Pool boiling offers a simple technique without moving parts and complex header arrangements. The evolution of passive enhanced pool boiling surfaces in recent years has been based on mechanistic considerations. 
Some of the augmentation features include providing additional surface area, additional nucleation sites and altering liquid wettability on the surface.

Placement of additional nucleation sites on the heater surface induces early nucleation and improved heat transfer [1-5]. The wicking mechanism in the porous structures further contributes to the liquid supply. Modulated porous coatings capable of generating separate liquid-vapor pathways were investigated by Liter and Kaviany [6]. Vapor venting pathways were created between two porous modulated structures through which bulk liquid was wicked in and fed to the nucleation sites. Min et al. [7] used compaction and sintering to achieve a 2D and 3D porous heat transfer surface. A CHF of $81.5 \mathrm{~W} / \mathrm{cm}^{2}$ was reported for a $2 \mathrm{D}$ structure with $\mathrm{n}$ pentane as the working fluid. $\mathrm{Li}$ and Peterson [2] used sintered porous mesh of varying thickness to understand the effect of thickness. A CHF of $347 \mathrm{~W} / \mathrm{cm}^{2}$ was reported, however the wall superheat was in excess of $60{ }^{\circ} \mathrm{C}$ which is undesirable as the HTC is significantly lower. This study helped identify an optimal thickness to strike a balance between availability of additional nucleation sites and thermal resistance offered by the porous coatings. In another publication, $\mathrm{Li}$ et al. [8] used modulated porous coatings to reach a CHF of $450 \mathrm{~W} / \mathrm{cm}^{2}$ at a wall superheat of 25 ${ }^{\circ} \mathrm{C}$. A maximum $\mathrm{HTC}$ of $200 \mathrm{~kW} / \mathrm{m}^{2 \circ} \mathrm{C}$ was obtained for this surface. The sintered porous coatings were placed on a circular area $(8 \mathrm{~mm}$ diameter) and the importance of vertical and lateral liquid replenishing pathways through the porous structure were highlighted in their study.

A novel microstructure which exhibited separate liquid-vapor pathways was investigated by Kandlikar [9] to enhance both CHF and HTC. A contoured fin structure was fabricated in which the motion of the bubble on the surface was governed by evaporation momentum force. The surface was manufactured using an embossing technique in which the edge location between the land and fin served as a preferential nucleation site. It was found that the bubble deflected along 
the contour of the land with subsequent addition of liquid through the sidewall regions of the fin. A CHF of $300 \mathrm{~W} / \mathrm{cm}^{2}$ was reached with an $\mathrm{HTC}$ of $629 \mathrm{~kW} / \mathrm{m}^{2 \circ} \mathrm{C}$. This structure formed the basis for developing the next generation of enhanced surfaces with separate liquid-vapor pathways.

Liquid wettability changes induced by hydrophobic and hydrophilic coatings is another type of enhancement technique. Betz et al. [10] conducted series of tests using hydrophilic and hydrophobic networked surfaces. They concluded that hydrophilicity improved the heat transfer performance whereas the hydrophobicity affected the nucleation characteristics. Graphene coatings are also employed to alter the liquid wettability. Recently, Jaikumar et al. [11] investigated the effect of graphene, graphene oxide and graphene quantum dot coatings. O'Hanley [12] studied the separate effects of wettability, porosity and roughness for a wide range of surfaces. They concluded that hydrophilic surface enhanced the CHF by $50 \%-60 \%$ while wettability and roughness had no effect on the CHF in the tested database. Rahman et al. [13] investigated the effect of bio-templated microstructures on a Si substrate based on liquid wettability changes. A CHF of $257 \mathrm{~W} / \mathrm{cm}^{2}$ was reported for these microstructures with a height of $32 \mu \mathrm{m}$.

Area augmented surfaces with liquid supply pathways have shown significant improvement in the heat transfer performance. Cooke and Kandlikar [14] developed open microchannels and reported heat fluxes in excess of $244 \mathrm{~W} / \mathrm{cm}^{2}$ at wall superheats of less than $10{ }^{\circ} \mathrm{C}$. Liquid supply to the nucleation sites was identified to occur through the channels enhancing the HTC by improving microconvection in the region. The architecture of the surface ensured that the liquid was supplied continuously to the nucleation sites which increased CHF. Roughening the surface has shown to have a direct effect on the CHF. This understanding was highlighted by Chu et al. 
[15] in their work. The silicon heat transfer surfaces had microstructures with different roughness values and dissipated heat fluxes in excess of $200 \mathrm{~W} / \mathrm{cm}^{2}$ with increasing roughness values.

In a more recent attempt to increase CHF and HTC simultaneously, Patil and Kandlikar $[3,16,17]$ used a combination of enhancement techniques. Porous coatings were deposited on open microchannel fin tops using a two-step electrodeposition process. A CHF of $325 \mathrm{~W} / \mathrm{cm}^{2}$ at a wall superheat of $7.3{ }^{\circ} \mathrm{C}$ was reported with water. They identified separate liquid-vapor pathways as the enhancement mechanism. Nucleation was shown to occur on the fin tops with liquid supply through the channel regions similar to a jet impingement like mechanism.

This mechanism was further explored in the work conducted by Jaikumar and Kandlikar [4]. Three configurations identified as sintered throughout, sintered fin tops and sintered channels were developed using $\mathrm{CNC}$ machining, screen printing and sintering techniques. Heat transfer mechanisms were identified for each configuration as shown in Fig 1. In a sintered throughout surface, the 'area augmented nucleation activity' was shown to be the governing mechanism. The 'bubble induced liquid jet impingement' with disrupted and sustained flow was responsible for the enhancement in sintered fin tops and sintered channels, respectively. For the selected microchannel dimensions $($ channel width $=762 \mu \mathrm{m}$, channel depth $=400 \mu \mathrm{m}$, fin width $=200$ $\mu \mathrm{m})$ the sintered throughout configuration was identified as the best performing surface. However, changing the microchannel dimensions is expected to affect the relative merits in each configuration as the liquid and vapor pathways are influenced in fundamentally different ways. 


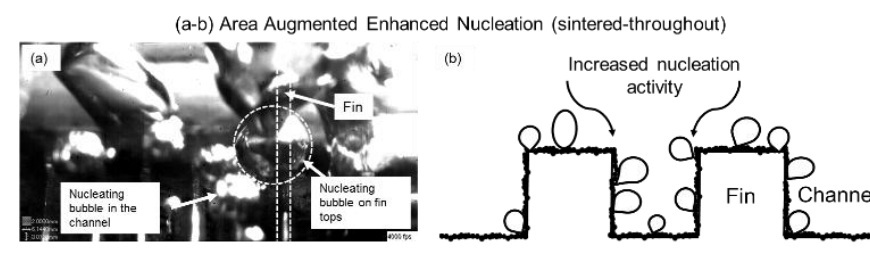

(c-d) Bubble Induced Liquid Jet Enhancement - Type - 1 (sintered-fin-tops)

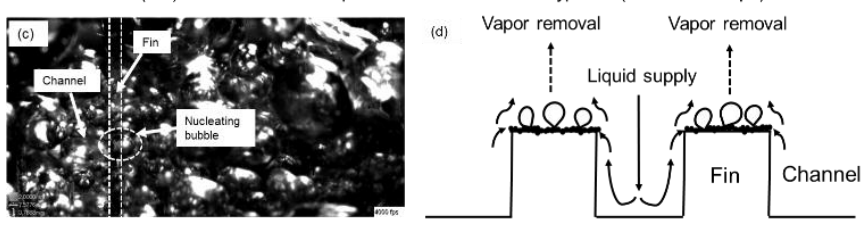

(e-f) Bubble Induced Liquid Jet Enhancement - Type - 2 (sintered-channels)

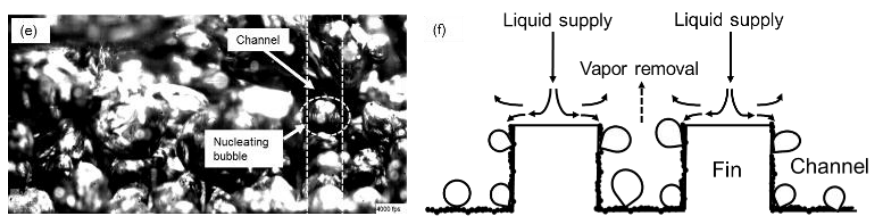

Figure 1. Proposed heat transfer mechanisms for selectively sintered open microchannels [4]

The channel width is seen to be an important parameter in governing the heat transfer mechanism. To explore its effect further, a detailed experimental investigation is carried out in this work to study the effect of channel width for each configuration (sintered-throughout, sintered-fin-tops and sintered channels). Although the channel dimensions investigated here do not cover a wide range for optimization purposes, the range selected is derived from the performance trends noted in the earlier investigations.

The objective of the current work is to study the effect of channel width on pool boiling performance for the three selectively sintered open microchannel configurations (i) sinteredthroughout, (ii) sintered-fin-tops, and (iii) sintered-channels. Literature has shown that channels widths over $1 \mathrm{~mm}$ significantly reduces the CHF $[3,14]$. Therefore in this study, three channel widths $-300 \mu \mathrm{m}, 500 \mu \mathrm{m}$ and $762 \mu \mathrm{m}$ for each configuration were investigated with distilled water at atmospheric pressure. The heat transfer mechanisms proposed in [4] are explored further by using high speed imaging to identify the driving mechanisms in each configuration to explain the parametric trends observed. 


\section{Experimental test setup}

A test setup similar to that described in [4] was used in this study and is shown in Fig. 2. It consists of three main components namely, (i) a test chip (ii) a heater block, and (iii) a water reservoir. The test chip was housed in a ceramic chip holder on the bottom garolite plate. Ceramic was chosen to minimize radial heat losses to the atmosphere. A quartz glass water bath was installed over the test chip to hold the boiling fluid and to aid in visualization. A water reservoir was assembled over the glass water bath to replenish water in the bath as and when required. Two openings were provided in the top aluminum plate for the auxiliary cartridge heater and the saturation thermocouple probe, respectively.

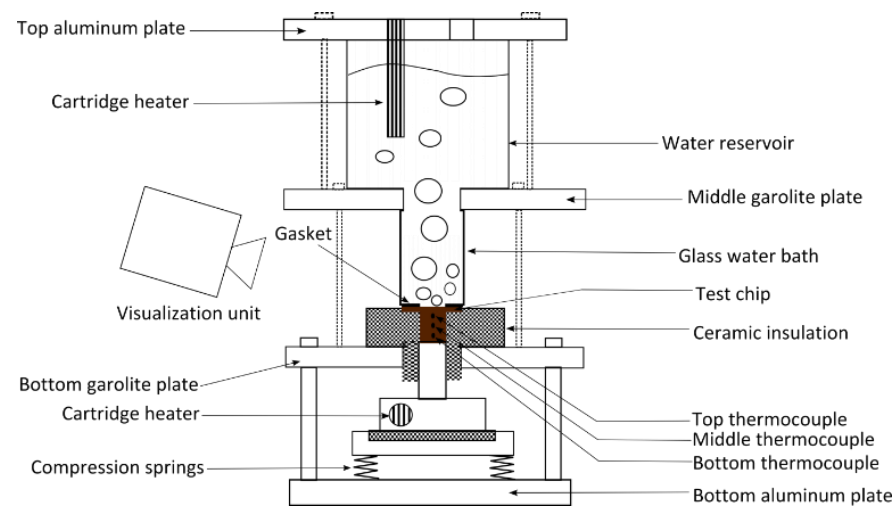

Figure 2. Pool boiling test setup used in this study [4] 
The bottom section of the test setup consisted of a copper heater block with $4 \times 200 \mathrm{~W}$ embedded cartridge heaters. The heater block was housed in a ceramic sleeve fitted in an aluminum base, which was supported on four compression springs to provide the required degree of movement to establish contact with the test chip and also to accommodate for any expansion during testing. The springs were supported on an $x-y$ stage to establish good contact with the test chip. Grafoil paper was added as a thermal interface material between the heater block and test chip to minimize contact resistance. A shaft connected the bottom garolite plate and the work table to ensure robustness of the setup.

A National Instruments cDaq-9172 data acquisition system with NI-9213 temperature module was used to record the temperature. A LabVIEWVR virtual instrument displayed and calculated the real-time surface temperature and heat flux.

\section{Test Section}

The test section used in this study consisted of a $17 \mathrm{~mm} \times 17 \mathrm{~mm}$ square copper chip with a central $10 \mathrm{~mm} \times 10 \mathrm{~mm}$ boiling region as shown in Fig 3(a). The excess area outside the boiling surface was covered with Kaptons ${ }^{\circledR}$ tape (thickness $\left.=75 \mu \mathrm{m}\right)$ to prevent this area from participating in heat transfer. This tape has a thermal conductivity of $0.12 \mathrm{~W} / \mathrm{m}-\mathrm{K}$ at $23^{\circ} \mathrm{C}$ and has been employed as a heat sealant for a wide range of applications [18]. Three thermocouples were inserted along the length of the test chip as shown in Fig. 3(b) to obtain accurate estimation of heat flux and surface temperature. It is noted that the area outside the boiling region on the chip is not exposed to the water. Although the Kaptons ${ }^{\circledR}$ tape is provided on this area, the lateral conduction in the copper induces heat loss to the surrounding air by natural convection only on the outside region of the chip exposed to air. To quantify this loss, a heat loss study is performed 
similar to Jaikumar and Kandlikar [19] which resulted in a loss of less than 3-4 W/ $\mathrm{cm}^{2}$ at higher heat fluxes. The heat flux was corrected and reported in Fig. 6, 8 and 10.

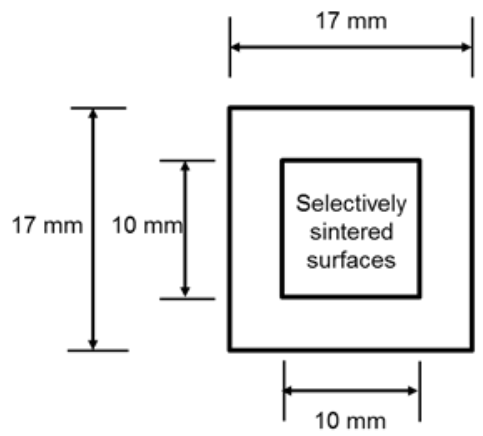

(a)

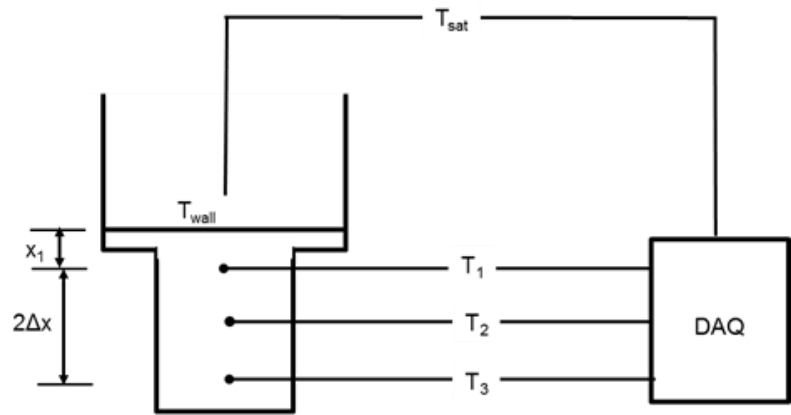

(b)

Figure 3. Schematic of the selectively sintered open microchannel copper test section used in this study

The manufacturing sequence for each test chip configuration was similar to that explained in [4]. A screen printing and sintering technique was employed for porous deposition and substrate bonding, respectively. A CNC machining process was used to fabricate the microchannels. Three surfaces with channel widths $300 \mu \mathrm{m}, 500 \mu \mathrm{m}$ and $762 \mu \mathrm{m}$ were manufactured for each configuration: (i) sintered-throughout, (ii) sintered fin-top, and (iii) sintered-channels to study the effect of channel width for each configuration and to understand the liquid and vapor pathways in selectively sintered open microchannels. The channel depth and fin width for all the surfaces were maintained constant at $400 \mu \mathrm{m}$ and $200 \mu \mathrm{m}$, respectively.

The heat flux to the test surface was calculated using Fourier 1-D conduction equation:

$$
q^{\prime \prime}=-k_{C u} \frac{d T}{d x}
$$

where, $k_{C u}$ is the thermal conductivity of copper and $d T / d x$ is the temperature gradient.

The temperature gradient $d T / d x$ was estimated using Taylor's backward series approximation

$$
\frac{d T}{d x}=\frac{3 T_{1}-4 T_{2}+T_{3}}{2 \Delta x}
$$


where, $T_{1}, T_{2}$ and $T_{3}$ are the temperatures corresponding to the thermocouples at the top, middle and bottom of the test chip, respectively.

The surface temperature is extrapolated using equation 1 as,

$$
T_{\text {wall }}=T_{1}-q^{\prime \prime}\left(\frac{x_{1}}{k_{C u}}\right)
$$

where, $T_{\text {wall }}$ is the temperature at the top of the fin and $x_{1}$ is the distance between the top thermocouple $\left(\mathrm{T}_{1}\right)$ and the boiling surface and is equal to $1.5 \mathrm{~mm}$ for all the surfaces investigated here. The corrected value of heat flux was used in eq. (3) to account for an accurate estimation of the surface temperature as the cross-section of the test chip changes from the point of measurement of temperature $\left(\mathrm{T}_{1}\right)$ and the location of extrapolated surface temperature located at the top of the fins. Figure 4 shows the temperature profile obtained by plotting distance between thermocouple locations on the $\mathrm{x}$-axis by assuming $\mathrm{T}_{3}$ (corresponding to the bottom thermocouple) is at 0 and the surface temperature is measured at a distance of $7.5 \mathrm{~mm}$ from $\mathrm{T}_{3}$. A linear line fit was established and the R-squared value was almost equal to unity indicating that a linear 1-D conduction existed between the measured temperatures and the extrapolated surface temperature value. 


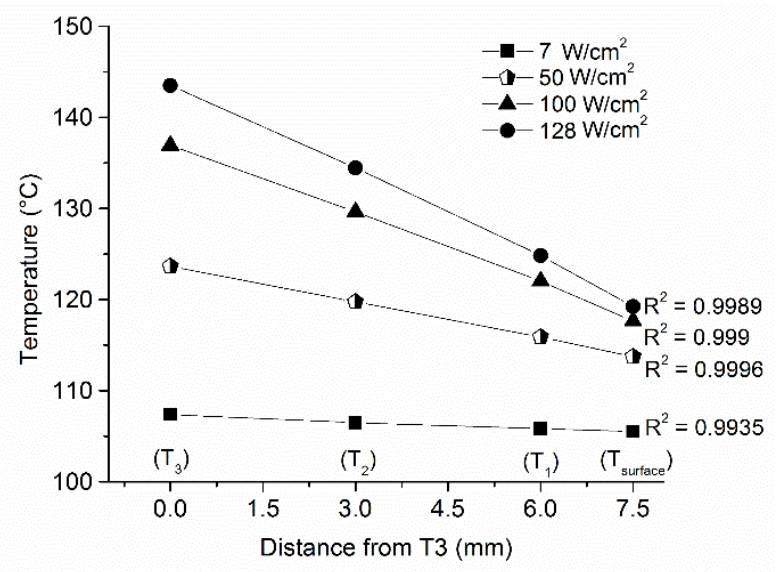

Figure 4. Temperature profile obtained for different heat fluxes plotted against distance from T3 to the surface temperature $\left(\mathrm{T}_{\text {surface }}\right)$ for the plain baseline copper chip 


\section{Uncertainty analysis}

An uncertainty analysis was performed similar to Jaikumar and Kandlikar [4].Thermal conductivity of copper, thermocouple calibration and the measurement of distance between thermocouples contributed to the uncertainty calculations. The method of partial sums was used to arrive at the uncertainty in heat flux, surface temperature and HTC. The variation of uncertainty with heat flux and HTC is shown in Figures 5 (a) and (b), respectively. The uncertainty at CHF which is the main region of interest is less than $6 \%$ for all the surfaces tested here. The uncertainty in HTC is high for the sintered-channels $-300 \mu \mathrm{m}$ as the wall superheat is very low for this chip. To prevent overcrowding of plots error bars are excluded in Fig. 6, 8 and 10.

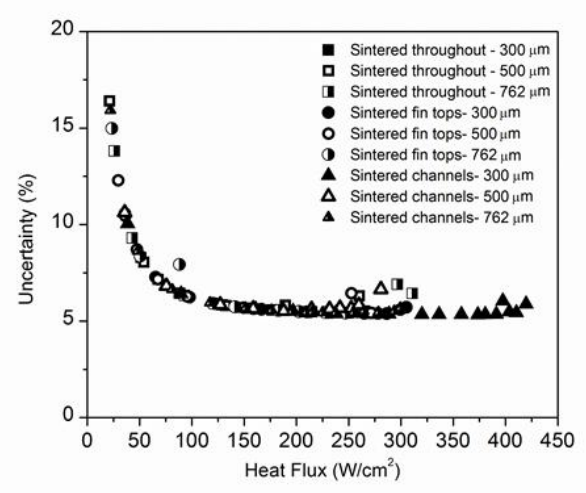

(a)

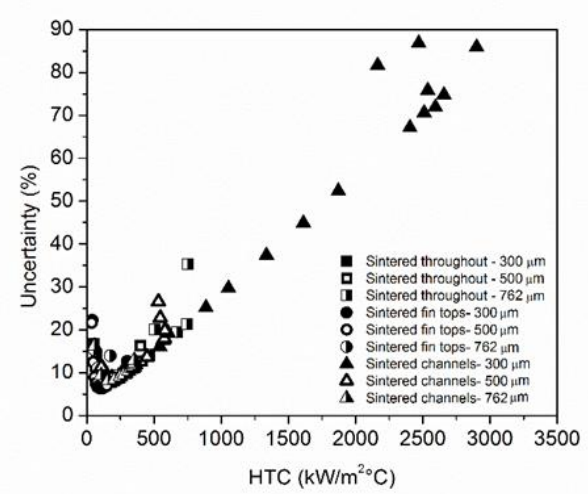

(b)

Figure 5. Variation of uncertainty with heat flux and HTC 


\section{Experimental Procedure}

The setup was assembled and distilled water was allowed to stand for a 24-hour period to check for leakage. The main and auxiliary heaters were powered by individual power supplies. The power to the test section from the main power supply was increased in larger steps $(5 \mathrm{~V})$ initially and in smaller steps $(<2 \mathrm{~V})$ closer to CHF. The pool boiling tests were conducted with distilled water at atmospheric pressure.

\section{Results}

Pool boiling curves relating the heat flux and wall superheat are used to characterize the performance of the surfaces tested here. The focus of the current work is to understand the effect of channel width on performance for the three selectively sintered configurations. Increased CHF and reduced wall superheat are desired for the efficient performance of the surfaces. A plain baseline chip was used for enhancement comparisons. This plain chip reached a CHF of 128 $\mathrm{W} / \mathrm{cm}^{2}$ at a wall superheat of $19.5^{\circ} \mathrm{C}$ with an $\mathrm{HTC}$ of $65 \mathrm{~kW} / \mathrm{m}^{2 \circ} \mathrm{C}$.

The effect of channel width on selectively coated configuration is studied as follows.

\section{a. Sintered throughout}

Figure 6 (a) shows the schematic of a sintered throughout surface geometry. Pool boiling curves based on the projected area are shown in Fig. 6 (b). Three channel widths tested (300 $\mu \mathrm{m}$, $500 \mu \mathrm{m}$ and $762 \mu \mathrm{m}$ ) and the plain chip data are included in this plot. A CHF of $313 \mathrm{~W} / \mathrm{cm}^{2}$ at a wall superheat of $7.5^{\circ} \mathrm{C}$ was obtained for a channel width of $762 \mu \mathrm{m}$. The $300 \mu \mathrm{m}$ and $500 \mu \mathrm{m}$ channel width test chips had a CHF of $265 \mathrm{~W} / \mathrm{cm}^{2}$ and $241 \mathrm{~W} / \mathrm{cm}^{2}$ at a wall superheat of $7.9{ }^{\circ} \mathrm{C}$ and $8{ }^{\circ} \mathrm{C}$, respectively. 
Figure 6 (c) shows the heat transfer performance plot. The general trend indicated that the HTC increased with heat flux. A maximum $\mathrm{HTC}$ of $304 \mathrm{~kW} / \mathrm{m}^{2 \circ} \mathrm{C}, 410 \mathrm{~kW} / \mathrm{m}^{2 \circ} \mathrm{C}$ and 565 $\mathrm{kW} / \mathrm{m}^{2 \circ} \mathrm{C}$ was obtained for $300 \mu \mathrm{m}, 500 \mu \mathrm{m}$ and $762 \mu \mathrm{m}$, respectively. The three chips showed significant enhancement in CHF and HTC over a plain chip indicating that the combination of enhancement techniques significantly improved the performance. Closer investigation revealed that wider channels performed better than narrower channels.

(a)

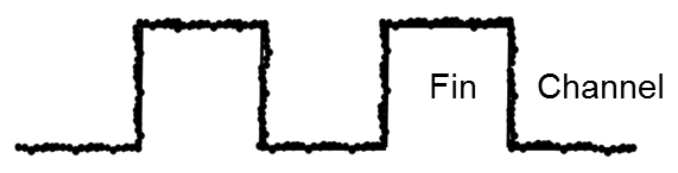

(c)

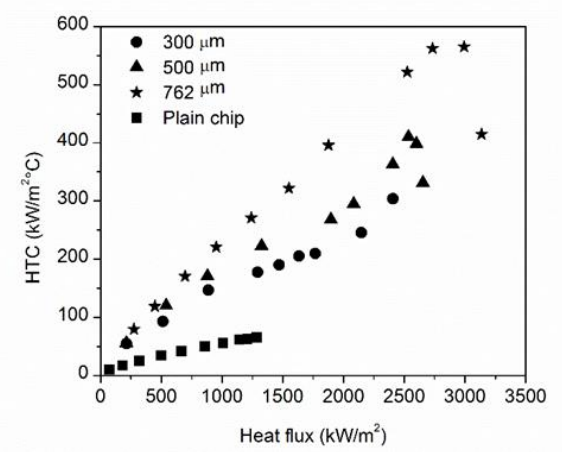

(b)

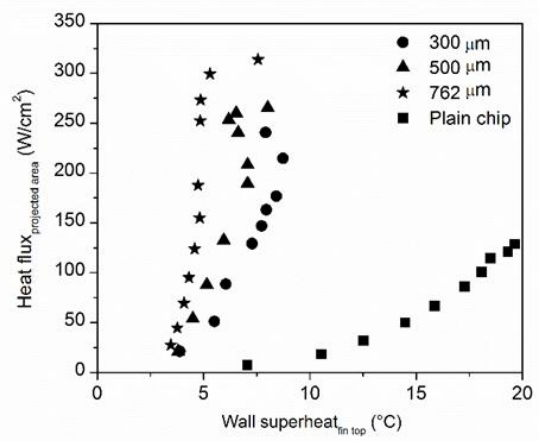

(d)

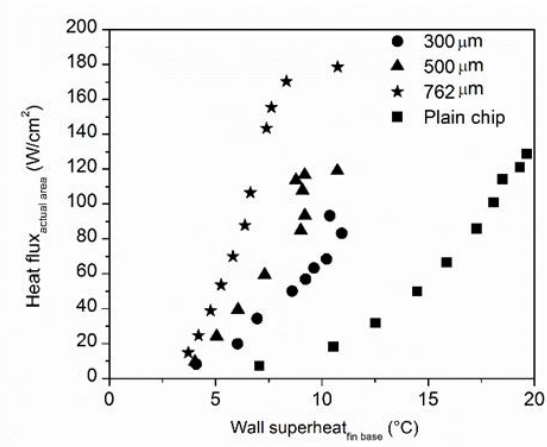

Figure 6. (a) Schematic of sintered-throughout configuration (b) Pool boiling curve for the three tested channel widths $(300 \mu \mathrm{m}, 500 \mu \mathrm{m}$ and $762 \mu \mathrm{m})$ with distilled water at atmospheric pressure using projected area and fin top temperature. The channel depth and fin width were maintained constant at 400 $\mu \mathrm{m}$ and $200 \mu \mathrm{m}$, respectively. (c) HTC based on the projected area and fin top temperature for the three tested surfaces (d) Area normalized boiling curves based on the actual surface area of the fins (without considering the wetted area provided by the sintered layer) and the temperature at the fin base.

Figure 6 (d) shows the normalized plot for the three channel widths tested here. The contribution of competing mechanisms can be understood from this plot. Area augmentation and improved liquid-vapor pathways are identified as competing mechanisms here. In the plot, the $300 \mu \mathrm{m}$ and $500 \mu \mathrm{m}$ channel width surfaces have area enhancement as their dominating 
mechanism while liquid pathways influenced by increased nucleation activity dominates in the $762 \mu \mathrm{m}$ channel width surface. The wall superheat is significantly reduced for all the surfaces investigated here due to availability of additional nucleation sites. The $762 \mu \mathrm{m}$ channel width surface showed significant enhancement in CHF over other surfaces. The CHF's based on the actual area are $93 \mathrm{~W} / \mathrm{cm}^{2}, 118 \mathrm{~W} / \mathrm{cm}^{2}$ and $178 \mathrm{~W} / \mathrm{cm}^{2}$ for the $300 \mu \mathrm{m}, 500 \mu \mathrm{m}$ and $762 \mu \mathrm{m}$ channel width surfaces, respectively.

In a previous publication [4], 'Area Augmented Enhanced Nucleation' was noted as the enhancement mechanism for the sintered throughout configuration. The mechanism essentially identifies chaotic liquid-vapor motion with liquid supply pathways generated in the normal and lateral direction as a result of this chaotic motion. However, facilitating pathways for liquid to enter the channels and feed to the nucleation sites is critical to further improve the performance. With this understanding the effect of channel width can be explained for this configuration. Increasing the channel width results in improved liquid pathways into the channels preventing dry-out condition. A wider channel offers larger number of liquid supply pathways to feed to the nucleation sites which is identified as the main reason for the $\mathrm{CHF}$ enhancement. The liquid supply pathways progressively decreases with the decreasing channel widths which is seen by the lower CHF values reported for the $500 \mu \mathrm{m}$ and $300 \mu \mathrm{m}$ channel widths. 
In support of the above description, high speed images were captured at $4000 \mathrm{fps}$ and at a low heat flux value $\left(\sim 15 \mathrm{~W} / \mathrm{cm}^{2}\right)$ using a Photron fastcam®. The visual access to the heater surface is impeded by the chaotic liquid-vapor motion which made imaging difficult at higher heat fluxes. Fig. 7 shows the images obtained for $300 \mu \mathrm{m}$ and $762 \mu \mathrm{m}$. The images (7a and 7c) show that the bubbles nucleated in the channels and on the fin tops. The figure also shows the schematic (b and d) of the proposed liquid-vapor pathways in the two configurations based on the images captured. The schematic identifies restricted liquid pathways in the narrow channels and availability of additional liquid pathways in the wider channels. As a result, a lower CHF value is observed in the $300 \mu \mathrm{m}$ channel width surface.

(a-b) Sintered throughout - $300 \mu \mathrm{m}$

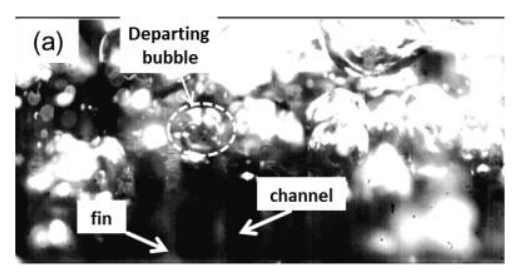

(b) Liquid entry paths hindered by vapor removal

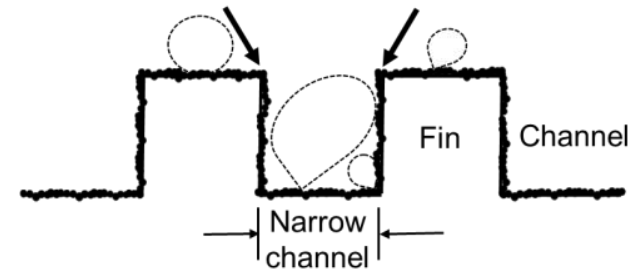

(c-d) Sintered throughout - $762 \mu \mathrm{m}$
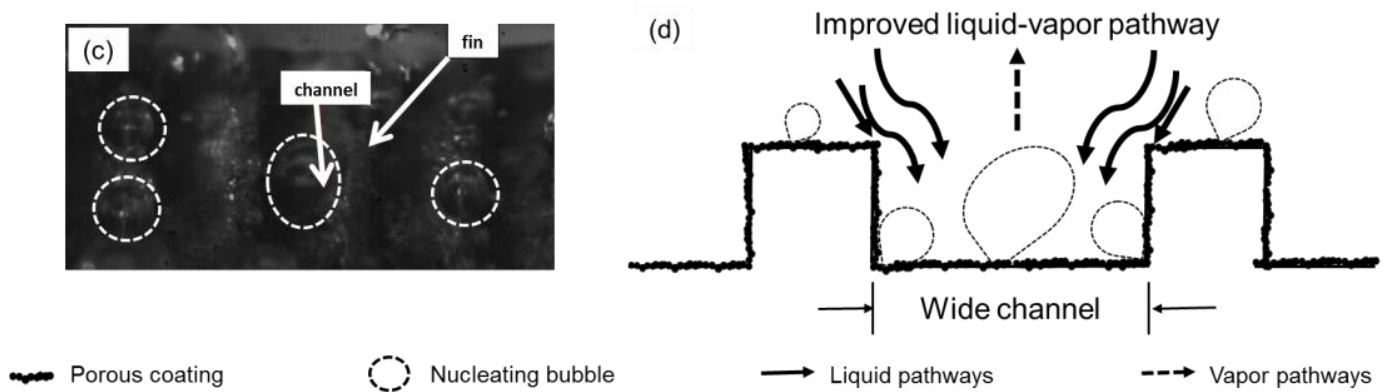

Figure 7. (a and c) Photographic image obtained for a channel width of $300 \mu \mathrm{m}$ showing bubble nucleation on the fin tops and inside the channels (b and d) Proposed heat transfer mechanisms for narrow and wide channel widths for sintered-throughout configuration. 


\section{b. $\quad$ Sintered-fin-tops}

The schematic and the scanning laser confocal microscopy image for a sintered fin-top configuration is shown in Fig. 8(a). Figure 8(b) shows the boiling curves obtained for the sintered-fin-top configuration. Similar to sintered-throughout, three channel widths - $300 \mu \mathrm{m}$, $500 \mu \mathrm{m}$ and $762 \mu \mathrm{m}$ were tested. A maximum CHF of $305 \mathrm{~W} / \mathrm{cm}^{2}$ was achieved with a channel width of $300 \mu \mathrm{m}$. The CHF's for the $500 \mu \mathrm{m}$ and $762 \mu \mathrm{m}$ were $272 \mathrm{~W} / \mathrm{cm}^{2}$ and $249 \mathrm{~W} / \mathrm{cm}^{2}$, respectively. The trend indicates that the narrower channels perform better than wider channels indicating that the liquid and vapor transport in this configuration is fundamentally different than the one seen in sintered-throughout.

Heat transfer performance curves are shown in Fig. 8 (c). Maximum HTCs of 308 $\mathrm{kW} / \mathrm{m}^{2 \circ} \mathrm{C}, 148 \mathrm{~kW} / \mathrm{m}^{2 \circ} \mathrm{C}$ and $364 \mathrm{~kW} / \mathrm{m}^{2 \circ} \mathrm{C}$ were obtained for the test chips with channel widths of $300 \mu \mathrm{m}, 500 \mu \mathrm{m}$ and $762 \mu \mathrm{m}$, respectively. A normalized plot showing the enhancement achieved is shown in Fig. 8 (d). The CHFs based on the actual area are $118 \mathrm{~W} / \mathrm{cm}^{2}, 121 \mathrm{~W} / \mathrm{cm}^{2}$ and $142 \mathrm{~W} / \mathrm{cm}^{2}$ for the $300 \mu \mathrm{m}, 500 \mu \mathrm{m}$ and $762 \mu \mathrm{m}$ channel width test surfaces, respectively. A similar trend to sintered-throughout is observed here with area enhancement being the dominating mechanism in the $300 \mu \mathrm{m}$ and $500 \mu \mathrm{m}$ surfaces and the separate liquid-vapor pathways being the driving mechanism in the $762 \mu \mathrm{m}$ surface. 
(a)

(a)

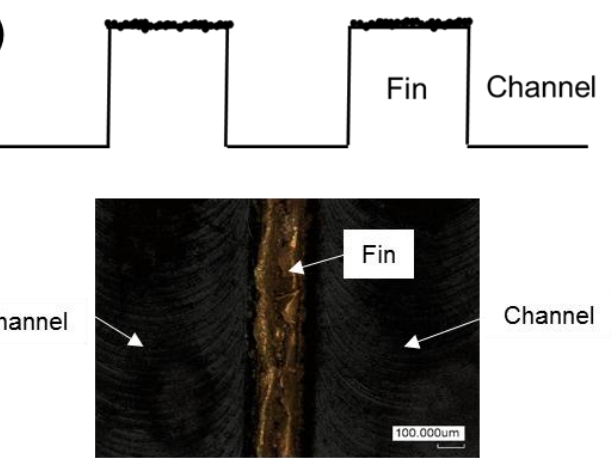

(c)

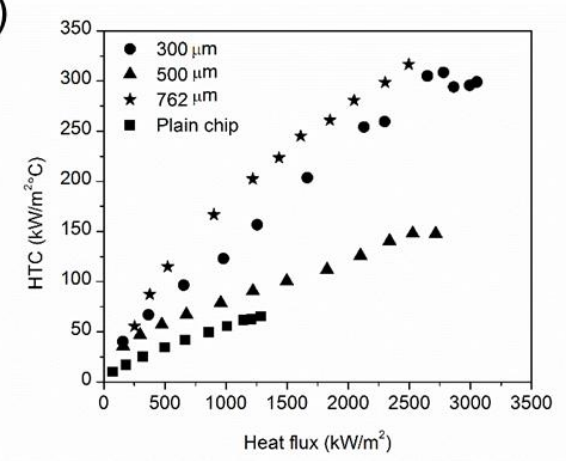

(b)

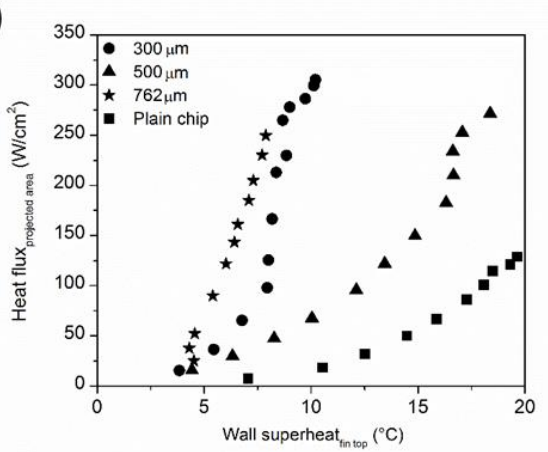

(d)

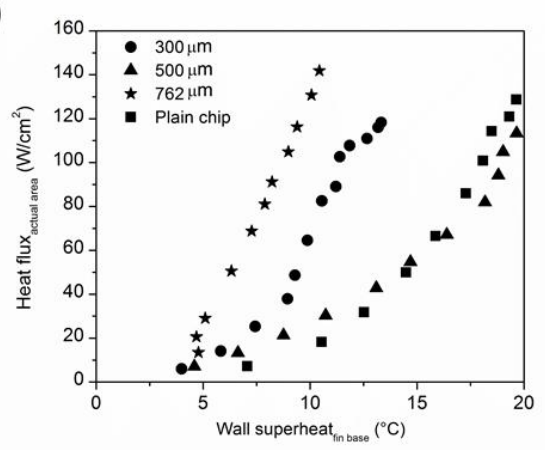

Figure 8. (a) Schematic of sintered-fin-top configuration and a scanning laser confocal image of the 762 $\mu \mathrm{m}$ channel width sintered-fin-top surface. The image shows sintered porous sintered coatings on fin tops with no deposits observed inside the channels (b) Pool boiling curves for the three tested channel widths $(300 \mu \mathrm{m}, 500 \mu \mathrm{m}$ and $762 \mu \mathrm{m})$ with distilled water at atmospheric pressure using projected area and fin top temperature (c) HTC based on the projected area and fin top temperature for the three tested surfaces (d) Normalized boiling curve based on the actual surface area (without considering the wetted area provided by the sintered layer) and the temperature at the fin base.

Two similar enhancement mechanisms were proposed for sintered-fin-tops and sinteredchannels as they exhibit separate liquid-vapor pathways [4].

- $\quad$ Bubble Induced Liquid Jet Enhancement, Type-1 (sintered-fin-tops)

- $\quad$ Bubble Induced Liquid Jet Enhancement ,Type-2 (sintered-channels)

In Type-1, separate liquid-vapor pathways are generated with nucleation occurring on the fin tops and subsequent liquid addition through the channel regions similar to a jet impingement mechanism. The increased CHF observed with decreasing channel widths can be attributed to the capability of the liquid to overcome the resistance after impinging on the base of the channels 
and be able to travel against gravity to feed to the nucleation sites. In a wide channel, the capability of the liquid to overcome gravity is significantly hampered due to the increased entrance length of the liquid in the channel base after impinging which results in decreased velocity and inability to the feed to the nucleation sites located on the fin tops. A further downside of this mechanism is that at higher surface temperatures nucleation cavities become active in the base of the channel thereby disrupting the existing convective flow and decreasing CHF. Furthermore, the porous nucleation sites are located on the $200 \mu \mathrm{m}$ fin width for the three channel widths tested. Since the area covered by the porous coating is significantly lower compared to sintered-throughout and sintered-channel configurations the wall superheats observed in this configuration set are relatively higher. Increasing the fin width has resulted in decreased performance as demonstrated by Patil and Kandlikar [3]. 
High speed images were taken to understand the underlying convective mechanism. The images for the $300 \mu \mathrm{m}$ and $762 \mu \mathrm{m}$ channel width surfaces suggested that bubbles nucleated on the fin tops with liquid addition through the channel regions as shown in Fig. 9 (a) and (c). However analyzing the mechanism further suggested that the liquid supply is affected by the channel width which in turn affects the heat transfer performance. A wider channel as shown in Fig. 9 (d) has a longer liquid flow path after impinging on the channel base where the liquid is unable to overcome the resistance of the sidewalls of the channels to feed to the nucleation sites. The liquid flow is further hampered by the nucleating bubbles in the channels at higher heat fluxes. The combined effect of increased flow length and nucleating bubbles inside the channels significantly reduces the CHF in the wider channels. The liquid flow in the narrow channel is improved as the liquid is able to impinge on the base and feed the nucleation sites. However, the nucleation in the channel regions disrupts the existing convective flow. In studying the channel widths employed here the $300 \mu \mathrm{m}$ channel width had a higher CHF compared to the $500 \mu \mathrm{m}$ and $762 \mu \mathrm{m}$ channel width test surfaces. 
(a-b) Sintered-fin-tops $300 \mu \mathrm{m}$

(a)

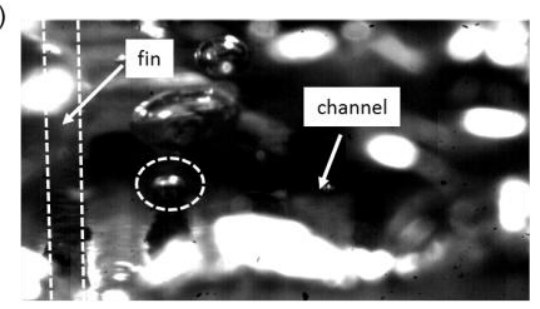

(b)

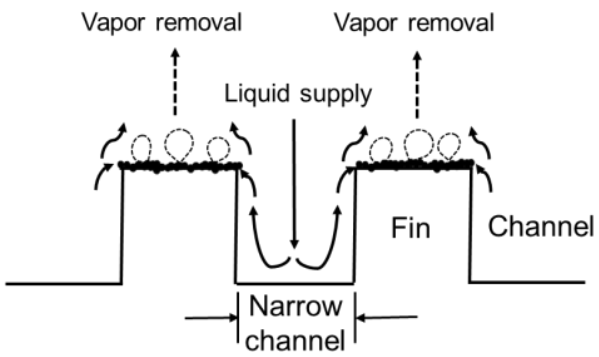

(c-d) Sintered-fin-tops $762 \mu \mathrm{m}$

(c)

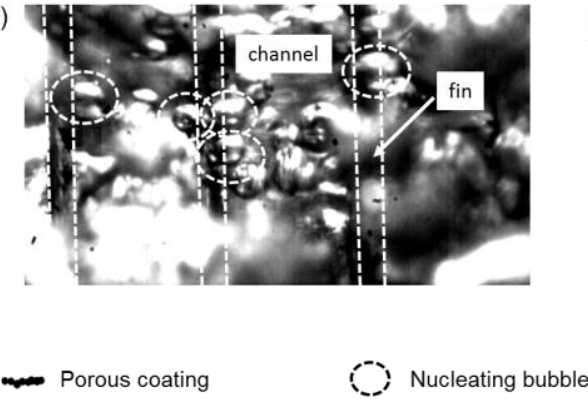

(d) Vapor removal

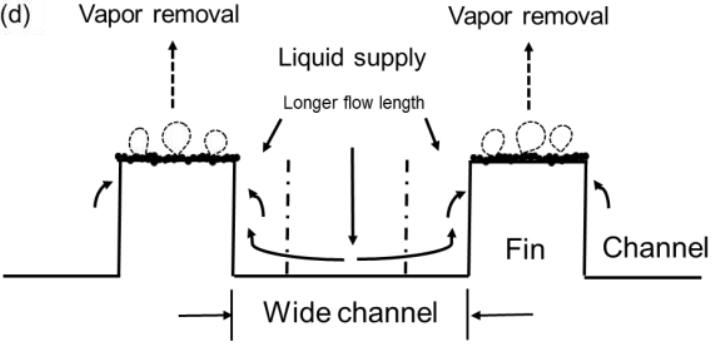

Figure 9. Photographic images and proposed heat transfer mechanisms for sintered-fin top configuration for channel widths of $300 \mu \mathrm{m}$ and $762 \mu \mathrm{m}$. The different liquid flow pathways for 'Bubble Induced Liquid Jet Mechanism-Type 1' for a narrow and a wide channel is identified here.

\section{c. $\quad$ Sintered-channels}

Figure 10 (a) shows the schematic and a confocal laser scanning microscope image of a sintered-channel configuration. In the image, porous coatings are seen in the channel base. The fin tops seem to be plain without any porous deposits. Figure 10 (b) shows the pool boiling curves obtained for three channel widths $(300 \mu \mathrm{m}, 500 \mu \mathrm{m}$ and $762 \mu \mathrm{m})$ based on the projected area with sintered-channel configuration. A CHF of $420 \mathrm{~W} / \mathrm{cm}^{2}$ at a wall superheat of $1.7{ }^{\circ} \mathrm{C}$ was obtained for the $300 \mu \mathrm{m}$ channel width. The $500 \mu \mathrm{m}$ and $762 \mu \mathrm{m}$ channel widths had CHF's of $281 \mathrm{~W} / \mathrm{cm}^{2}$ and $299 \mathrm{~W} / \mathrm{cm}^{2}$, respectively. The wall superheats for the $500 \mu \mathrm{m}$ and $762 \mu \mathrm{m}$ channel width surfaces were $5.2{ }^{\circ} \mathrm{C}$ and $8.4^{\circ} \mathrm{C}$, respectively. Fig. 10 (c) shows the heat transfer performance plot. The heat dissipating capability of the surface can be established using this plot. An unprecedented maximum HTC of $2.9 \mathrm{MW} / \mathrm{m}^{2 \circ} \mathrm{C}$ was obtained for a channel width $300 \mu \mathrm{m}$. Although the uncertainty is very high at this value of HTC (see Fig. 5b) due to extremely small 
wall superheat and very high heat flux, it still represents a significant improvement over any other boiling surface. To the best of the authors' knowledge, this is the highest reported HTC in literature for pool boiling with water at atmospheric pressure. The $500 \mu \mathrm{m}$ and $762 \mu \mathrm{m}$ surfaces had a maximum $\mathrm{HTC}$ of $599 \mathrm{~kW} / \mathrm{m}^{2 \circ} \mathrm{C}$ and $363 \mathrm{~kW} / \mathrm{m}^{2 \circ} \mathrm{C}$, respectively.

Figure 10 (d) shows the area-normalized plot with the wall superheat based on the temperature at the base of the fin. The sintered-channel configuration yielded CHFs (based on the actual surface area) of $162 \mathrm{~W} / \mathrm{cm}^{2}, 126 \mathrm{~W} / \mathrm{cm}^{2}$ and $172 \mathrm{~W} / \mathrm{cm}^{2}$ respectively for the $300 \mu \mathrm{m}$, $500 \mu \mathrm{m}$ and $762 \mu \mathrm{m}$ channel width surfaces, respectively. The results suggest that significant enhancement is achieved based on the actual area indicating that separate liquid-vapor pathways was the driving mechanism ('Bubble Induced Liquid Jet Enhancement - Type 2') in this configuration.

(a)

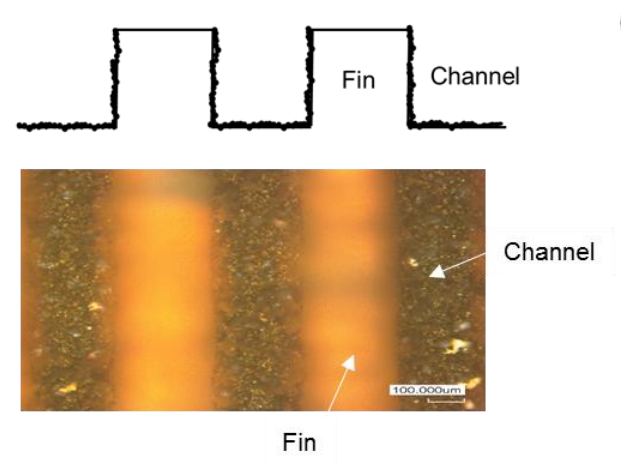

(c)

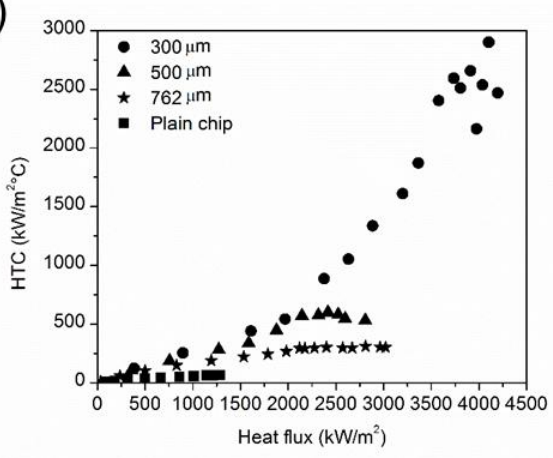

(b)

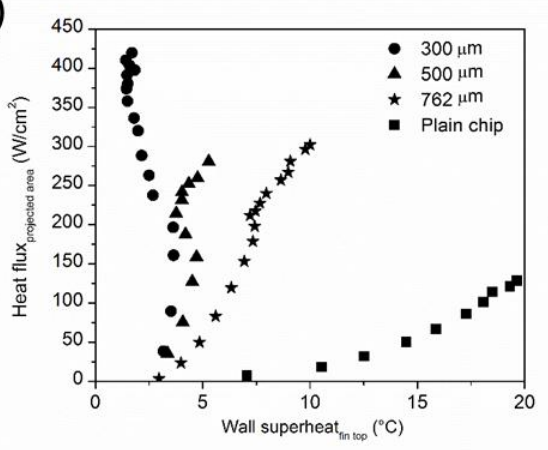

(d)

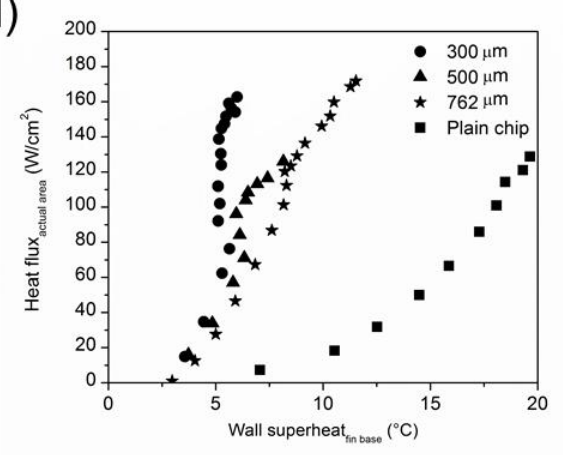

Figure 10. (a) Schematic of sintered-channel configuration with a confocal laser scanning microscopy image taken at 10X magnification (b) Pool boiling curve for the three tested channel widths ( $300 \mu \mathrm{m}, 500$ 
$\mu \mathrm{m}$ and $762 \mu \mathrm{m}$ ) with distilled water at atmospheric pressure using projected area and fin top temperature (c) HTC based on the projected area and fin top temperature for the three tested surfaces (d) Area normalized boiling curve based on the actual surface area (without considering the wetted area provided by the sintered layer) and the temperature at the fin base.

The key idea in this mechanism was that bubbles nucleated inside the channels with liquid addition through the fin top regions. The liquid transport from the fin tops to the channel bottom was governed by capillary motion, wicking inside the porous coatings and gravitational motion. A distinct feature of this configuration is that nucleation is always favored inside the channels and the convective mechanism is sustained at higher heat fluxes making this configuration superior to other mechanisms - 'Area Augmented Enhanced Nucleation' for sintered-throughout and 'Bubble Induced Liquid Jet Enhancement - Type 1' for sintered-fintops. The wall superheat is always lower at the fin top as compared to the channel surface. This prevents any adverse bubble nucleation on the fin tops that would otherwise obstruct the liquid return pathways. 
However in this mechanism the jet impingement on the fin tops results in certain fraction of liquid turning towards the bulk as against entering the channels. This can be detrimental in a wider channel as the demand for liquid supply is higher due to the increased number of nucleation sites. Since the quantity of liquid supplied through the fin tops is lesser in a wider channel, the $762 \mu \mathrm{m}$ channel width has the lowest CHF. This mechanism is different from the sintered-throughout (lacking jet impingement) as the liquid supply to the channels works in fundamentally different ways. On the other hand, a narrow channel ensures continuous supply of liquid to the nucleation sites ensuring complete rewetting till the wicking limit is reached inside the porous coatings leading to $\mathrm{CHF}$. The superior rewetting mechanism coupled with sustained convective flow is critical to improve the performance as exhibited by the $300 \mu \mathrm{m}$ channel width test chip.

High speed video images were taken to identify the liquid and vapor pathways in the 300 $\mu \mathrm{m}$ and $762 \mu \mathrm{m}$ channel width (Fig. 11 (a) and (c)). Imagining was done at lower heat fluxes of $\sim 15 \mathrm{~W} / \mathrm{cm}^{2}$ for both the surfaces. The images suggested that a significant number of bubbles were seen to emerge inside the channels in the $762 \mu \mathrm{m}$ chip. The increased vapor generation rate in the wider channels demands more liquid and also serves as hindrance to the liquid supply pathways in the channel whereas the narrower channels provides improved pathways for liquid to rewet the channel efficiently. Increasing the fin width has shown to decrease the CHF [3]. A sintered-channel configuration with a fin width of $500 \mu \mathrm{m}$ and a channel width of $300 \mu \mathrm{m}$ was also investigated in this study to see if the same trend is observed. The CHF for this surface was $195 \mathrm{~W} / \mathrm{cm}^{2}$ showing a significant reduction in performance. 
(a-b) Sintered-channels - $300 \mu \mathrm{m}$
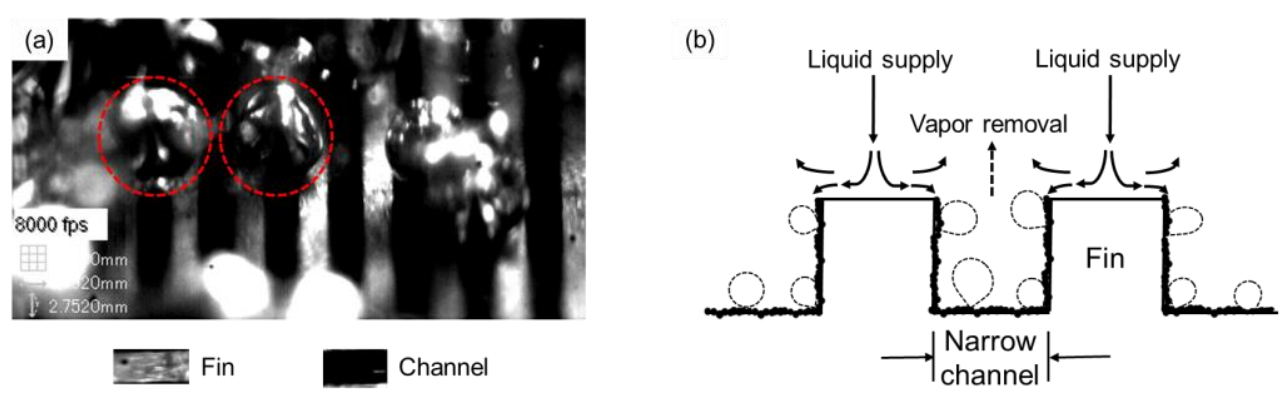

(c-d) Sintered-channels - $762 \mu \mathrm{m}$
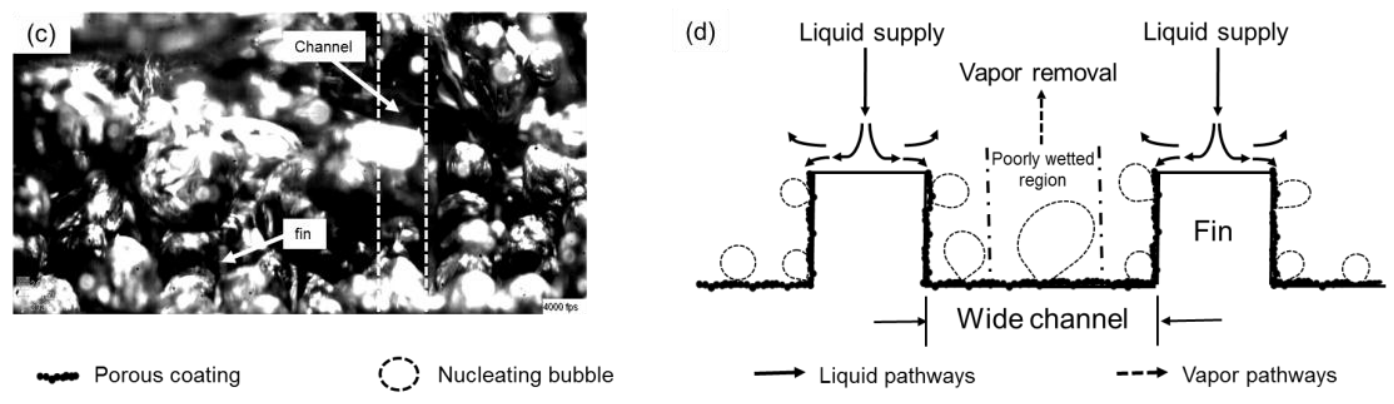

Figure 11. (a and c) High speed images showing bubble nucleation inside the channels. The $762 \mu \mathrm{m}$ channel width surface has more number of bubbles emerging due to availability of additional nucleation sites. (b and d) Proposed heat transfer mechanisms showing jet impingement on the fin tops resulting in liquid supply to the channels for a narrow $(300 \mu \mathrm{m})$ and wide channel $(762 \mu \mathrm{m})$ in a sintered-channel configuration.

\section{d. Enhancement mechanism comparisons}

In the sintered-throughout configuration, the primary enhancement mechanism is driven by increased nucleation activity which causes liquid agitation in the immediate vicinity of the departing bubbles. The liquid supply pathways are influenced by the channel width were a wider channel is expected to supply liquid more efficiently than a narrow channel. However there is randomness in this mechanism. The bubbles departing from the fin tops could also contribute to the liquid supply to the channels. There are no organized liquid supply and vapor removal pathways. Area enhancement and availability of additional nucleation sites dominate the mechanism of increased nucleation activity. In one such mechanistic approach in this configuration, it can be said that the liquid pathways entering the channels (i) laterally in to the channels and (ii) vertically from sidewalls through wicking from the fin tops enhance the 
performance. In the wide channels, these pathways are more in number and increase the CHF by preventing dry-out. However any nucleation on the fin tops may further disrupt the flow of liquid into the channels. In addition, the liquid also needs to be supplied to the nucleation sites located on the fin tops which further starves this configuration of liquid supply. In a narrow channel (300 $\mu \mathrm{m})$, the area enhancement is the highest which requires more number of liquid pathways to feed the nucleation sites. The increased nucleation activity inhibits the liquid supply leading to early CHF. However in a wider channel (762 $\mu \mathrm{m})$ the liquid supply is sustained for a longer period due to the decreased nucleation sites compared to the $300 \mu \mathrm{m}$ surface.

However in the sintered-channel geometry, the location of porous coatings inside the channels influences bubble nucleation to occur in the channels. The liquid supply occurs through the fin tops. In such a system with separate liquid-vapor flow fields, the liquid transport to the channel regions is influenced by capillary wicking through the coatings on the sidewall regions of the channel. In a wide channel $(700 \mu \mathrm{m})$, the capillary wicking is insufficient to wet the central regions of the channel base which results in dry-out condition leading to early CHF. In the narrow channel $(300 \mu \mathrm{m})$, the wetting is superior where the liquid is able to reach the channel base and feed the nucleation sites. These mechanisms at play are significantly amplified at higher heat fluxes which sustain the mechanism and enhance the performance.

In the sintered-fin top geometry, the enhancement mechanism is driven by liquid transport in the channels. The liquid impinges on the base of the channels similar to a jet impingement like mechanism and forces the liquid to turn towards the nucleation sites located on the fin tops. This separate liquid-vapor pathways work differently in a narrow and wide channel. In a wide channel, the liquid entrance length is larger than a narrow channel. This results in decreased flow velocity and inability of the liquid to reach the fin tops. In a narrow channel the 
competing mechanisms are sustained and wet the fin tops to supply liquid. However in such a setup, bubbles nucleating in the channels at higher heat fluxes create some order of randomness in the liquid supply and vapor removal pathways in both the narrow and wide channels.

\section{e. $\quad$ Comparison to literature}

Figure 12 shows the comparison of the best performing pool boiling curves obtained here (762 $\mu \mathrm{m}$ - sintered throughout, $300 \mu \mathrm{m}$ - sintered-fin-top and $300 \mu \mathrm{m}$ - sintered-channel surfaces) with different enhancement structures reported in literature. The values reported in literature have shown different mechanistic approaches taken to reach a CHF of $300 \mathrm{~W} / \mathrm{cm}^{2}$ or a HTC of $100 \mathrm{~kW} / \mathrm{m}^{2 \circ} \mathrm{C}$. The CHF reported here for the a $300 \mu \mathrm{m}$ sintered-channel configuration is in close comparison to that reported by Li et al. [8] however the wall superheat and the HTC reported in their study is $26^{\circ} \mathrm{C}$ and $172 \mathrm{~kW} / \mathrm{m}^{2 \circ} \mathrm{C}$ at $\mathrm{CHF}$. The wall superheat and $\mathrm{HTC}$ reported here are $1.7{ }^{\circ} \mathrm{C}$ and $2.468 \mathrm{MW} / \mathrm{m}^{2 \circ} \mathrm{C}$ at $\mathrm{CHF}$, respectively. The $\mathrm{CHF}$ reported at wall superheats below $10{ }^{\circ} \mathrm{C}$ by Kandlikar [9], Mori and Okayuma [20], Patil and Kandlikar [3] and Cooke and Kandlikar [14] are less than $325 \mathrm{~W} / \mathrm{cm}^{2}$ whereas the CHF achieved here is $420 \mathrm{~W} / \mathrm{cm}^{2}$.

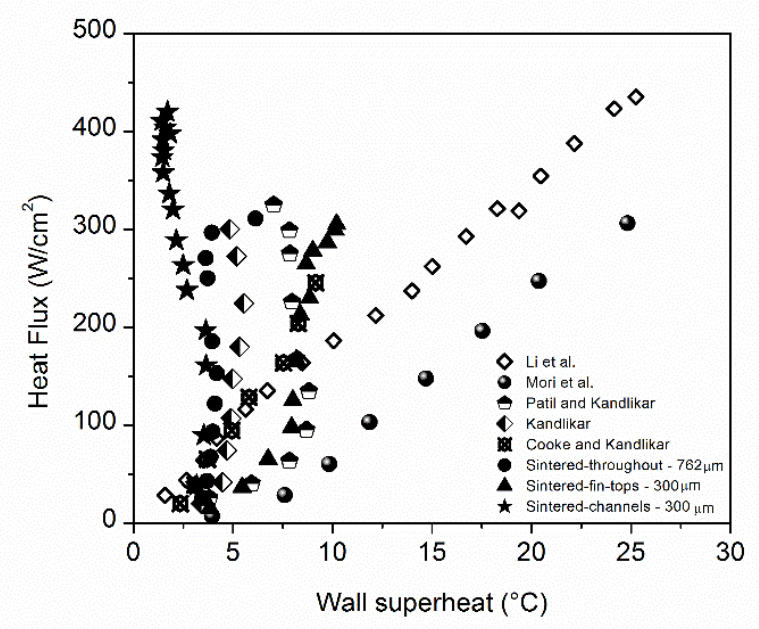

Figure 12. Pool boiling performance comparison with different structures reported in literature with water at atmospheric pressure 
Table 1 summarizes the maximum HTC and CHF values obtained with different enhancement structures and mechanisms in literature. The sintered channel configuration with $300 \mu \mathrm{m}$ channel width performs exceptionally well with an ultra-high performance CHF of 420 $\mathrm{W} / \mathrm{cm}^{2}$ and a maximum $\mathrm{HTC}$ of $2.9 \mathrm{MW} / \mathrm{m}^{2 \circ} \mathrm{C}$.

Table 1. HTC and CHF comparison with literature

\begin{tabular}{|c|c|c|}
\hline Enhancement structure & CHF W/cm ${ }^{2}$ & HTC kW/m ${ }^{2 \circ} \mathrm{C}$ \\
\hline $\begin{array}{l}\text { Sintered-throughout }-762 \\
\mu \mathrm{m} \text { (current study) }\end{array}$ & 313 & 565 \\
\hline $\begin{array}{l}\text { Sintered-fin-tops }-300 \\
\mu \mathrm{m} \text { (current study) }\end{array}$ & 305 & 308 \\
\hline $\begin{array}{l}\text { Sintered-channel - } 300 \\
\mu \mathrm{m} \text { (current study) }\end{array}$ & 420 & 2900 \\
\hline $\begin{array}{l}\text { Sintered modulated } \\
\text { porous coating }[8]\end{array}$ & 450 & 200 \\
\hline Contoured fin [9] & 300 & 629 \\
\hline $\begin{array}{l}\text { Porous open microchannel } \\
\text { fin top [3] }\end{array}$ & 325 & 414 \\
\hline $\begin{array}{l}\text { Honey comb with nano } \\
\text { structures [20] }\end{array}$ & 310 & 119 \\
\hline Open microchannel [14] & 244 & 244 \\
\hline
\end{tabular}

\section{Conclusions}

A detailed experimental investigation was conducted to study the effect of channel width on pool boiling performance for sintered-throughout, sintered-fin-tops and sintered-channel configurations. Three channel widths $-300 \mu \mathrm{m}, 500 \mu \mathrm{m}$ and $762 \mu \mathrm{m}$ were tested for each configuration with distilled water at atmospheric pressure. The microchannels were fabricated using a CNC machine while the porous coating and substrate bonding were achieved by a screen printing and a sintering process, respectively. Liquid and vapor pathways for each configuration set was captured using high speed camera. The following conclusions are drawn from this study 
i. In the sintered-throughout configuration, a wider channel (channel width $=762 \mu \mathrm{m})$ had a higher CHF than a narrower channel (channel width $=300 \mu \mathrm{m}$ ). The CHF values for the $300 \mu \mathrm{m}, 500 \mu \mathrm{m}$ and $762 \mu \mathrm{m}$ were $241 \mathrm{~W} / \mathrm{cm}^{2}, 265 \mathrm{~W} / \mathrm{cm}^{2}$ and 313 $\mathrm{W} / \mathrm{cm}^{2}$, respectively. Maximum HTCs of $304 \mathrm{~kW} / \mathrm{m}^{2 \circ} \mathrm{C}, 410 \mathrm{~kW} / \mathrm{m}^{2 \circ} \mathrm{C}$ and 565 $\mathrm{kW} / \mathrm{m}^{2 \circ} \mathrm{C}$ were obtained for the $300 \mu \mathrm{m}, 500 \mu \mathrm{m}$ and $762 \mu \mathrm{m}$, respectively. The high speed images suggested that majority of the nucleation occurred inside the channels. The driving mechanism in this configuration is the chaotic liquid-vapor motion. However, facilitating liquid pathways is critical in enhancing the CHF. Therefore a wider channel, with additional liquid pathways to feed to the nucleation sites had a higher CHF and HTC compared to a narrower channel.

ii. Narrower channels $(300 \mu \mathrm{m})$ performed better than wider channels $(762 \mu \mathrm{m})$ in the sintered-fin-top configuration. Separate liquid-vapor pathways were observed with bubbles nucleating on the fin tops and liquid supply through the channel regions by a jet impingement like feeding mechanism. Channel width had an important role to play as it affected the liquid transport to the nucleation sites. High speed images obtained suggested that the wider channels had a longer flow length and the liquid was unable to feed to the nucleation sites located on the fin tops. The convective mechanism in this configuration was further disrupted due to the bubbles nucleating in the channels as a result of the manufacturing process employed. The CHF values for the $300 \mu \mathrm{m}, 500 \mu \mathrm{m}$ and $762 \mu \mathrm{m}$ channel widths were $305 \mathrm{~W} / \mathrm{cm}^{2}, 272 \mathrm{~W} / \mathrm{cm}^{2}$ and $249 \mathrm{~W} / \mathrm{cm}^{2}$, respectively. 
iii. While analyzing the sintered-channel configuration, it was observed that the narrower channels performed better than the wider channels. A record CHF of $420 \mathrm{~W} / \mathrm{cm}^{2}$ at a wall superheat of $1.7^{\circ} \mathrm{C}$ was observed for the $300 \mu \mathrm{m}$ channel width test surface. This translated to an enhancement of $228 \%$ in CHF compared to a plain chip. A record $\mathrm{HTC}$ of $2900 \mathrm{~kW} / \mathrm{m}^{2 \circ} \mathrm{C}$ was obtained with the same surface, indicating a $4361 \%$ improvement over a plain chip. The $500 \mu \mathrm{m}$ and $762 \mu \mathrm{m}$ channel width surfaces had a CHF of $281 \mathrm{~W} / \mathrm{cm}^{2}$ and $299 \mathrm{~W} / \mathrm{cm}^{2}$, respectively. High speed images suggested that the jet impingement on the fin tops contributed to liquid feed in to the channels. In a wide channel $(762 \mu \mathrm{m})$, the liquid feeding mechanism is insufficient to wet the entire channel surface which led to early CHF. However, in the $300 \mu \mathrm{m}$ wide channels, the jet impingement was sufficient to continuously wet the channel regions till the CHF was reached. The mechanism proposed for the sintered-channel configuration is expected to sustain the convective flow at higher heat fluxes making it superior to the sintered-throughout and sintered-fin tops configurations as reflected by the performance.

\section{Acknowledgments}

The work was conducted in the Thermal Analysis, Microfluidics and Fuel Cell laboratory at Rochester Institute of Technology in Rochester, NY. The authors like to thank Andrew Greeley for his efforts in fabricating the surfaces. The authors would also like to acknowledge the financial support provided by NSF under CBET Award No. 1335927 (Project title - Ultra High Boiling Performance on Nano/Microstructured Surfaces through Electrodeposition of Copper and Graphene). 


\section{References}

[1] WEBB, R. L., 1981, "Nucleate Boiling on Porous Coated Surfaces," Heat Transf. Eng., 4(3-4), pp. 71-82.

[2] Li, C., and Peterson, G. P., 2007, "Parametric Study of Pool Boiling on Horizontal Highly Conductive Microporous Coated Surfaces," J. Heat Transf., 129(11), p. 1465.

[3] Patil, C. M., and Kandlikar, S. G., 2014, "Pool boiling enhancement through microporous coatings selectively electrodeposited on fin tops of open microchannels," Int. J. Heat Mass Transf., 79, pp. 816-828.

[4] Jaikumar, A., and Kandlikar, S. G., 2015, "Enhanced pool boiling heat transfer mechanisms for selectively sintered open microchannels," Int. J. Heat Mass Transf., 88, pp. 652-661.

[5] A.E.Bergles, and M.C.Chyu, 1982, "Characteristics of Nucleate Pool Boiling From Porous Metallic Coatings," J. Heat Transf., 104, pp. 279-285.

[6] Liter, S. G., and Kaviany, M., 2001, "Pool-boiling CHF enhancement by modulated porouslayer coating: theory and experiment," Int. J. Heat Mass Transf., 44(22), pp. 4287-4311.

[7] Min, D. H., Hwang, G. S., Usta, Y., Cora, O. N., Koc, M., and Kaviany, M., 2009, “2-D and 3-D modulated porous coatings for enhanced pool boiling," Int. J. Heat Mass Transf., 52(11-12), pp. 2607-2613.

[8] Li, C. H., Li, T., Hodgins, P., Hunter, C. N., Voevodin, A. A., Jones, J. G., and Peterson, G. P., 2011, "Comparison study of liquid replenishing impacts on critical heat flux and heat transfer coefficient of nucleate pool boiling on multiscale modulated porous structures," Int. J. Heat Mass Transf., 54(15-16), pp. 3146-55.

[9] Kandlikar, S. G., 2013, "Controlling bubble motion over heated surface through evaporation momentum force to enhance pool boiling heat transfer," Appl. Phys. Lett., 102(5), p. 051611.

[10] Betz, A. R., Xu, J., Qiu, H., and Attinger, D., 2010, “Do surfaces with mixed hydrophilic and hydrophobic areas enhance pool boiling?," Appl. Phys. Lett., 97(14), pp. 141909 141909-3.

[11] Jaikumar, A., Santhanam, K. S., Kandlikar, S. G., Raya, I. B. P., and Raghupathi, P., 2015, "Electrochemical Deposition of Copper on Graphene with High Heat Transfer Coefficient," Meet. Abstr., (33), pp. 1891-1891.

[12] O’Hanley, H., Coyle, C., Buongiorno, J., McKrell, T., Lin-wen Hu, Rubner, M., and Cohen, R., 2013, "Separate effects of surface roughness, wettability, and porosity on the boiling critical heat flux," Appl. Phys. Lett., 103(2), p. 024102 (5 pp.).

[13] Rahman, M. M., King, S. M., Olceroglu, E., and McCarthy, M., 2012, "Nucleate boiling on biotemplated nanostructured surfaces," ASME 2012 International Mechanical Engineering Congress and Exposition, IMECE 2012, November 9, 2012 - November 15, 2012, American Society of Mechanical Engineers, pp. 2801-2808.

[14] Cooke, D., and Kandlikar, S. G., 2012, "Effect of open microchannel geometry on pool boiling enhancement," Int. J. Heat Mass Transf., 55(4), pp. 1004-13.

[15] Chu, K.-H., Enright, R., and Wang, E. N., 2012, "Structured surfaces for enhanced pool boiling heat transfer,” Appl. Phys. Lett., 100(24), pp. 241603-241603-4. 
[16] Patil, C. M., Santhanam, K. S. V., and Kandlikar, S. G., 2014, "Development of a two-step electrodeposition process for enhancing pool boiling," Int. J. Heat Mass Transf., 79, pp. 989-1001.

[17] Patil, C. M., and Kandlikar, S. G., "Enhanced boiling with selective placement of nucleation sites."

[18] "http://www.dupont.com/content/dam/dupont/products-and-services/membranes-andfilms/polyimde-films/documents/DEC-Kapton-summary-of-properties.pdf."

[19] Jaikumar, A., and Kandlikar, S. G., 2015, "Enhanced Pool Boiling For Electronics Cooling Using Porous Fin Tops on Open Microchannels With FC-87," Appl. Therm. Eng.

[20] Mori, S., Mt Aznam, S., and Okuyama, K., 2015, "Enhancement of the critical heat flux in saturated pool boiling of water by nanoparticle-coating and a honeycomb porous plate," Int. J. Heat Mass Transf., 80, pp. 1-6. 


\section{List of Figures}

Figure 1. Proposed heat transfer mechanisms for selectively sintered open microchannels [4]

Figure 2. Pool boiling test setup used in this study [4]

Figure 3. Schematic of the selectively sintered open microchannel copper test section used in this study

Figure 4. Temperature profile obtained for different heat fluxes plotted against distance from $\mathrm{T} 3$ to the surface temperature ( $\left.\mathrm{T}_{\text {surface }}\right)$ for the plain baseline copper chip

Figure 5. Variation of uncertainty with heat flux and HTC

Figure 6. (a) Schematic of sintered-throughout configuration (b) Pool boiling curve for the three tested channel widths $(300 \mu \mathrm{m}, 500 \mu \mathrm{m}$ and $762 \mu \mathrm{m})$ with distilled water at atmospheric pressure using projected area and fin top temperature. The channel depth and fin width were maintained constant at $400 \mu \mathrm{m}$ and $200 \mu \mathrm{m}$, respectively. (c) HTC based on the projected area and fin top temperature for the three tested surfaces (d) Area normalized boiling curves based on the actual surface area and the temperature at the fin base

Figure 7. (a and c) Photographic image obtained for a channel width of $300 \mu \mathrm{m}$ showing bubble nucleation on the fin tops and inside the channels ( $b$ and d)Proposed heat transfer mechanisms for narrow and wide channel widths for sintered-throughout configuration.

Figure 8. (a) Schematic of sintered-fin-top configuration and a scanning laser confocal image of the $762 \mu \mathrm{m}$ channel width sintered-fin-top surface. The image shows sintered porous sintered coatings on fin tops with no deposits observed inside the channels (b) Pool boiling curves for the three tested channel widths $(300 \mu \mathrm{m}, 500 \mu \mathrm{m}$ and $762 \mu \mathrm{m})$ with distilled water at atmospheric pressure using projected area and fin top temperature (c) HTC based on the projected area and fin top temperature for the three tested surfaces (d) Normalized boiling curve based on the actual surface area and the temperature at the fin base.

Figure 9. Photographic images and proposed heat transfer mechanisms for sintered-fin top configuration for channel widths of $300 \mu \mathrm{m}$ and $762 \mu \mathrm{m}$. The different liquid flow pathways for 'Bubble Induced Liquid Jet Mechanism-Type 1' for a narrow and a wide channel is identified here. 
Figure 10. (a) Schematic of sintered-channel configuration with a confocal laser scanning microscopy image taken at 10X magnification (b) Pool boiling curve for the three tested channel widths $(300 \mu \mathrm{m}, 500 \mu \mathrm{m}$ and $762 \mu \mathrm{m})$ with distilled water at atmospheric pressure using projected area and fin top temperature (c) HTC based on the projected area and fin top temperature for the three tested surfaces (d) Area normalized boiling curve based on the actual surface area and the temperature at the fin base.

Figure 11. (a and c) High speed images showing bubble nucleation inside the channels. The $762 \mu \mathrm{m}$ channel width surface has more number of bubbles emerging due to availability of additional nucleation sites. ( $b$ and d) Proposed heat transfer mechanisms showing jet impingement on the fin tops resulting in liquid supply to the channels for a narrow (300 $\mu \mathrm{m})$ and wide channel $(762 \mu \mathrm{m})$ in a sintered-channel configuration.

Figure 12. Pool boiling performance comparison with different structures reported in literature with water at atmospheric pressure 


\section{List of Tables}

Table 1. HTC and CHF comparison with literature 